\title{
KUALITAS PELAYANAN IZIN MENDIRIKAN BANGUNAN (IMB) PADA DINAS PENANAMAN MODAL DAN PELAYANAN TERPADU SATU PINTU KABUPATEN POLEWALI MANDAR
}

\author{
Andi Muh. Alwi Yusuf ${ }^{1}$ \\ ${ }^{1}$ Prodi Ilmu Pemerintahan, Fakultas Ilmu Sosial dan Ilmu Pemerintahan \\ Universitas Al Asyariah Mandar \\ Email: bayusapuad@gmail.com \\ Munawir Arifin² \\ ${ }^{2}$ Prodi Ilmu Pemerintahan, Fakultas Ilmu Sosial dan Ilmu Pemerintahan \\ Universitas Al Asyariah Mandar \\ Email: munawirarif86@gmail.com
}

\begin{abstract}
$\operatorname{ABSTRACT}$
The purpose of this research is to find out how the quality of building permit services in the investment service and integrated one door service of polewali mandar regency. The research method used is descriptive research with a qualitative approach. The results of this study are, a study of the quality of IMB services in Polewali Mandar district has increased in terms of ease of IMB services, although there are still found obstacles from the community regarding the maintenance of $I M B$, namely in the file requirements. The conclusion of this research is DPMPTSP in facilitating the community in taking care of the IMB, namely by having a website where to facilitate the public to obtain information about the IMB requirements and IMB management flow. The suggestion this research is DPMPTSP district of Polewali Mandar in order to maintain the quality of services related to IMB so that the community judges good and does not think less well of the services provided by DPMPTSP.
\end{abstract}

\section{ABSTRAK}

Penelitian ini bertujuan adalah Untuk mengetahui Bagaimana Kualitas pelayanan Izin Mendirikan Bangunan (IMB) pada Dinas Penanaman Modal dan Pelayanan Terpadu Satu Pintu Kabupaten Polewali Mandar. Metode penelitian yang digunakan adalah penelitian deskriptif dengan pendekatan kualitatif. Hasil penelitian ini adalah, Studi tentang kualitas pelayanan IMB di Kabupaten Polewali Mandar telah mengalami peningkatan dalam hal kemudahan pelayanan IMB walaupun masih ada ditemukan kendala dari masyarakat terhadap pengurusan IMB yaitu di persyaratan berkas.Kesimpulan penelitian ini adalah DPMPTSP dalam memudahkan masyarakat dalam mengurus IMB yaitu dengan adanya website dimana untuk mempermudah masyarakat mendapatkan informasi seputar 
persyaratan IMB dan alur pengurusan IMB. Saran penelitian ini adalah DPMPTSP Kabupaten Polewali Mandar agar mempertahankan kualitas pelayanan terkait IMB supaya masyarakat menilai baik dan tidak berpendapat kurang baik terhadap pelayanan yang diberikan oleh PTSP.

Kata Kunci: Quality, Service, Building Permit (IMB).

\section{PENDAHULUAN}

Kehidupan sehari-hari tidak terpisahkan dari pelayanan yang di dapatkan pada penyelenggara pelayanan dalam memenuhi kebutuhan dan hak bagi individu maupun kelompok. Pelayanan menurut Suparlan (2000:35) ialah sebuah usaha pemberian, bantuan, ataupun pertolongan pada orang lain, baik dengan berupa materi atau juga non materi agar orang tersebut bisa mengatasi masalahnya itu sendiri.

Pelayanan publik mempunyai ruang lingkup yang sangat luas dan mencakup di beberapa bidang salah satu pelayanan yang kita temui, dan terkadang terjadi permasalahan dalam proses pengurusannya yaitu Izin Mendirikan Bangunan (IMB). Pada dasarnya pelayanan publik ialah kegiatan dalam memenuhi hak dan kebutuhan masyarakat dengan kepastian hukum yang jelas,kesamaan hak dan akurat mengenai pelayanan yang diberikan oleh penyelenggara pelayanan publik yang berwenang terhadap apa yang dibutuhkan oleh pelanggan.

Mengenai permasalahan yang akan diteliti oleh penulis menyangkut pelayanan publik saat ini pada bidang perizinan khususnya Izin Mendirikan Bangunan (IMB) pada DPM dam PTSP, terkait judul yang di ambil adalah bagaimana kualitas pelayanan terkait Izin Mendirikan Bangunan. Sejak tiga tahun terakhir atau sebelum diresmikan DPM dan PTSP tahun 2015 kita ketahui bersama bahwa sarana dan prasarana di PTSP sebagai penunjang dalam memberikan pelayanan kepada masyarakat itu masih kurang memadai dan indeks kepuasan masyarakat sebagai tolok ukur dalam mengetahui kualitas pelayanan masih kurang memberikan kepuasan terhadap pelanggan. Seperti yang kita ketahui DPMPTSP baru berjalan dua tahun dalam memberikan pelayanan yang tentunya berkualitas kepada masyarakat yakni pada tahun 2017 sampai 2018 itu dibuktikan dengan adanya suatu kegiatan yang dilakukan oleh DPMPTSP yaitu Survey Kepuasan Masyarakat (SKM) yang dimana mengsurvey masyarakat yang telah terbit izin IMB-nya.

Hasil observasi yang didapat oleh penulis di lokasi penelitian adalah walaupun DPMPTSP sudah resmi terbentuk pada tahun 2016 namun sampai sekarang ini masih ada masyarakat di Polewali Mandar yang belum memiliki IMB inilah yang menjadi hasil observasi awal yang didapat di DPMPTSP. 
Seperti yang kita ketahui yang menjadi penyebab atau kendala yang sering terjadi ialah kurangnya kualitas pelayanan pada pelayanan IMB yang efisien dan efektif masih harus ditingkatkan ,etos kerja pelayanan masih kurang memuaskan,ketetapan pada pelayanan IMB masih harus dibenahi dan sangat perlunya pemberitahuan atau arahan yang akurat lagi mengenai pengurusan IMB ini.

\section{METODE PENELITIAN}

\section{Jenis Penelitian}

Penelitian deskriptif adalah karakteristik penelitian yang mengungkapkan secara spesifik berbagai fenomena sosial dan alam yang ada di dalam kehidupan masyarakat. Spesifik yang dimaksud disini lebih dekat pada hubungan, dampak, dan cara penyelesainnya yang diungkapkan.

Penelitian deskriptif bertujuan untuk memberikan gambaran tentang bagaimana Dinas Penanaman Modal dan Pelayanan Terpadu Satu Pintu (DPMPTSP) memberikan pelayanan prima kepada masyarakat pada bidang Perizinan khususnya menyangkut pelayanan pengurusan Izin Mendirikan Bangunan (IMB).

\section{Teknik Pengumpulan Data}

\section{Observasi}

Peneliti melakukan pengamatan secara langsung di lapangan pengamatan disebut observer. Teknik ini dilakukan dengan cara mengamati dan mencatat secara sistematik gejala-gejala yang diselidiki (Supardi, 2006:88). Informasi yang diperoleh dari hasil observasi adalah ruang (tempat), pelaku, kegiatan, objek, perbuatan, kejadian atau peristiwa. Alasan peneliti melakukan observasi adalah untuk menyajikan gambaran realistik perilaku atau kejadian.

\section{Dokumentasi}

Dokumentasi nerupakan sumber data yang digunakan untuk melengkapi penelitian atau proses sistematis dalam melakukan pengumpulan, pencarian,pemakaian serta penyediaan dokumen untuk mendapatkan keterangan,penerangan pengetahuan serta bukti.

\section{Wawancara}

Wawancara adalah proses tanya jawab dalam penelitian yang berlangsung secara lisan dalam mana dua orang atau lebih bertatap muka mendengarkan secara langsung informasi-informasi atau keteranganketerangan (Supardi, 2006:99). Wawacanra dikenal dengan interview adalah pengumpulan data dengan mengajukan pertanyaan secara langsung oleh 
pewancara kepada responden dan jawaban responden dicatat atau direkam. Wawacanra dilakukan untuk mendapat hasil terhadap objek yang diteliti.

\section{Teknik Analisis Data}

Teknik analisis data disebut juga dengan proses pengolahan data yang dilakukan guna pembuktian dan penyajian data menjadi informasi yang akurat. Analisis data yang saya gunakan adalah analisis kualitatif dengan proses analisis kualitatif yang mendasarkan pada adanya hubungan semantis antar variabel yang sedang diteliti. Peneliti menggunakan analisis kualitatif untuk mendapatkan makna hubungan variabel-variabel sehingga dapat digunakan untuk menjawab masalah yang dirumuskan dalam penelitian . Prinsip pokok analisis kualitatif mengolah dan menganalisis data-data yang terkumpul menjadi data yang sistematik, teratur, terstruktur, dan mempunyai makna.

Teknik analisis data kualitatif diperoleh dari hasil wawacanra, koesioner, observasi, dan dokumen. Menurut Miles dan Huberman, (Emzir, 2010) terdapat tiga macam kegiatan analisis data kualitatif, yaitu :

1) Reduksi Data

Data yang diperoleh di lapangan jumlahnya cukup banyak, untuk itu perlu dicatat secara teliti dan rinci. Mereduksi data berarti : merangkum, memilih hal-hal yang pokok, memfokuskan pada hal-hal yang penting, dicari tema dan polanya dan membuang yang tidak perlu.

2) Model Data (data display)

Display data dalam penelitian kualitatif bisa dilakukan dalam bentuk : uraian singkat, bagan, hubungan antar kategori, flowchart dan sebagainya, yang paling sering digunakan untuk menyajikan data dalam penelitian kualitatif dengan teks yang bersifat naratif. Selain dalam bentuk naratif, display data dapat juga berupa grafik, matriks, network (jejaring kerja).

3) Penarikan/Verifikasi kesimpulan

Kesimpulan awal yang dikemukakan masih bersifat sementara, dan akan berubah bila tidak ditemukan bukti-bukti yang kuat yang mendukung pada tahap pengumpulan data berikutnya. Namun bila kesimpulan memang telah didukung oleh bukti-bukti yang valid dan konsisten saat peneliti kembali ke lapangan mengumpulkan data, maka kesimpulan yang dikemukakan merupakan kesimpulan yang kredibel (dapat dipercaya). 


\section{HASIL PENELITIAN}

\section{Gambaran Umum Lokasi Penelitian}

Dinas Penanaman Modal dan Pelayanan Terpadu Satu Pintu atau DPMPTSP yang sebelumnya melekat pada Dinas Pendapatan Daerah setelah tahun 2016 dibentuknya kelembagaan baru lahirlah DPMPTSP, dan DPMPTSP merupakan kelembagaan negara yang diatur oleh PERMENDAGRI No. 100 tahun 2016 tentang Penanaman Modal dan Pelayanan Terpadu Satu Pintu serta aturan BKPM (Badan Koordinasi Penanaman Modal). DPMPTSP resmi dibentuk pada tanggal 28 November 2016 yang merupakan implementasi dari PP No. 18 Tahun 2016 Tentang Perangkat Daerah sehingga DPMPTSP ini adalah salah satu OPD di bidang perizinan dan yang menjadi dasar hukumnya adanya Peraturan Daerah No. 12 Tahun 2016 Tentang Pembentukan dan Susunan Organisasi Perangkat Daerah Kabupaten Polewali Mandar. Agar mencapai kinerja yang bagus harus selalu berpatokan pada visi dan misi serta tujuan dan strategi, sehingga yang diharapkan tentang pelayanan yang prima dapat terwujud. Adapula visi dan misi DPM dan PTSP yang ingin dicapai adalah sebagai berikut : Visi "Terwujudnya Pelayanan Terpadu Satu Pintu dan Iklim Investasi yang lebih baik berdasarkan Budaya Sipamandar" Misi: Meningkatkan Promosi dan Kerjasama Investasi serta sarana dan prasarana penanaman modal, Mewujudkan Pelayanan Perizinan dan Non Perizinan yang berkualitas serta tertib administrasi berdasarkan budaya sipamandar, Mengembangkan pengelolaan perizinan, data dan sistem Informasi Meningkatkan perlindungan, pengawasan dan pengendalian.

\section{Hasil Penelitian}

Pada tahun 2017 sampai 2018 pelayanan yang berkualitas sudah dapat dirasakan oleh pelanggan terkait IMB dengan DPMPTSP melakukan program kegiatan dalam mengukur atau menilai bagaimana kualitas pelayanan terkait IMB yang kegiatan tersebut adalah "Survey Kepuasan Masyarakat" (SKM) kegiatan ini mengsurvey masyarakat yang telah terbit izinnya dengan mengacu kepada 14 unsur pelayanan yang menjadi bahan untuk mengukur bagaimana kualitas pelayanan itu sendiri dengan demikian hasil dari SKM yaitu Indeks Kepuasan Masyarakat (IKM) mendapat nilai B "Baik".

\section{Tabel 1}

Mekanisme Pelayanan Izin Mendirikan Bangunan (IMB)

\begin{tabular}{|c|c|}
\hline NO & MEKANISME PELAYANAN \\
\hline 1 & Pemohon mencari informasi diloket informasi atau website \\
\hline 2 & Memberikan penjelasan layanan perizinan, menyerahkan formulir dan \\
\hline
\end{tabular}




\begin{tabular}{|c|c|}
\hline & memberikan informasi petunjuk pengisian \\
\hline 3 & $\begin{array}{l}\text { Pemohon mengisi formulir dan menyerahkan berkas permohonan kepada } \\
\text { petugas pendaftaran }\end{array}$ \\
\hline 4 & $\begin{array}{l}\text { Menerima dan memeriksa kelengkapan berkas permohonan, berkas yang } \\
\text { lengkap diregistrasi dan diserahkan ke unit back office lalu pemohon } \\
\text { diberikan tanda terima berkas sedangkan berkas tidak lengkap akan } \\
\text { dikembalikan kepada pemohon untuk dilengkapi }\end{array}$ \\
\hline 5 & $\begin{array}{l}\text { Menerima dokumen kelengkapan berkas dari front office dan memberikan } \\
\text { paraf persetujuan untuk di proses ketahap selanjutnya }\end{array}$ \\
\hline 6 & $\begin{array}{l}\text { Menerima berkas permohonan, membubuhi tanda terima berkas dan } \\
\text { menyiapkan administrasi pemrosesan sesuai standar prosedur }\end{array}$ \\
\hline 7 & $\begin{array}{l}\text { Tim teknis menerima surat pengantar dan berkas permohonan untuk } \\
\text { dilakukan proses penerbitan rekomendasi teknis/surat penolakan }\end{array}$ \\
\hline 8 & $\begin{array}{l}\text { Menyiapkan naskah surat izin apabila direkomendasikan dapat diterbitkan } \\
\text { atau menyiapkan surat penolakan apabila direkomendasikan ditolak }\end{array}$ \\
\hline 9 & $\begin{array}{l}\text { Ka. Bidang memeriksa, membubuhi paraf selanjutnya diserahkan kepada } \\
\text { Ka. DPMPTSP }\end{array}$ \\
\hline 10 & $\begin{array}{l}\text { Menandatangani surat izin, jika izin dipandang memenuhi persyaratan } \\
\text { untuk diterbitkan dan dikembalikan pada bidang pengelolaan dan } \\
\text { pengendalian apabila dipandang belum memennuhi persyaratan }\end{array}$ \\
\hline 11 & $\begin{array}{l}\text { Melakukan registrasi surat izin yang sudah ditandatangani kepala } \\
\text { DPMPTSP, kemudian mengarahkan pemohon untuk melakukan } \\
\text { penyelesaian administrasi pembayaran dan sekaligus menyerahkan lembar } \\
\text { survey kepuasan }\end{array}$ \\
\hline 12 & Pemohon melakukan pembayaran retribusi di kasir \\
\hline 13 & $\begin{array}{l}\text { Menerima pembayaran, mencatat dan menyerahkan bukti penyelesaian } \\
\text { administrasi (kwitansi pelunasan) dan SSRD }\end{array}$ \\
\hline 14 & $\begin{array}{l}\text { Pemohon menyerahkan bukti kwitansi pelunasan dan lembar survey } \\
\text { kepuasan pada petugas penyerahan dokumen perizinan }\end{array}$ \\
\hline 15 & $\begin{array}{l}\text { Melakukan pencatatan serah terima dan menyerahkan dokumen perizinan } \\
\text { kepada pemohon dan menerima lembar survey kepuasan dari pemohon }\end{array}$ \\
\hline
\end{tabular}

Dari tabel di atas dapat kita ketahui bahwa aparatur pada DPMPTSP sudah memberikan kemudahan bagi masyarakat yang mengurus IMB dengan adanya susunan tahap-tahap mekanisme pelayanan mulai dari pemohon datang ke DPMPTSP untuk mendapat informasi mengenai pengurusan IMB sampai diterbitkannya dokumen IMB. Tujuan dari mekanisme pelayanan itu sendiri untuk memperjelas agar masyarakat tidak lagi berpendapat bahwa prosedur pelayanan di DPMPTSP itu berbelit-belit dan tidak terjangkau. 


\section{Tabel 2}

Jumlah Bangunan Yang Telah Mendapat IMB dari DPMPTSP Kabupaten Polewali Mandar Tahun 2018

\begin{tabular}{|c|l|l|}
\hline NO & \multicolumn{1}{|c|}{ Bulan } & \multicolumn{1}{c|}{ Jumlah IMB Terbit } \\
\hline 1 & Januari & 264 \\
\hline 2 & Februari & 287 \\
\hline 3 & Maret & 29 \\
\hline 4 & April & 68 \\
\hline 5 & Mei & 165 \\
\hline 6 & Juni & 23 \\
\hline 7 & Juli & 130 \\
\hline 8 & Agustus & 218 \\
\hline 9 & September & 148 \\
\hline 10 & Oktober & 133 \\
\hline 11 & November & 69 \\
\hline 12 & Desember & 154 \\
\hline & Jumlah & 1688 \\
\hline
\end{tabular}

Sumber: DPMPTSP Kabupaten Polewali Mandar, Tahun 2018

Dari tabel di atas menunjukkan bahwa kesadaran masyarakat dalam mengurus IMB dari bulan januari sampai desember tahun 2018 mengalami peningkatan, walaupun masih ada penurunan di bulan maret, Juni, dan November, tetapi lebih dominan yang peningkatannya. Peningkatan pengurusan IMB yang terbanyak berada di bulan Februari yaitu 287 yang terbit IMB. Semua ini tidak terlepas dari peran Buapti Daerah dan aparatur DPMPTSP dalam memberikan sosialisasi kepada masyarakat tentang persyaratan mengurus IMB serta tata cara proses penerbitan IMB yang diatur pada PERMENDAgRI No. 32 Tahun 2010 tentang Pedoman Pemberian Izin Mendirikan Bangunan.

\section{Pembahasan}

\section{Kualitas Pelayanan Izin Mendirikan Bangunan}

Pada tahun 2017 dan 2018 DPMPTSP sudah mulai menyusun perencanaan terkait pelayanan IMB kepada masyarakat, dan melakukan perubahan baik dari sarana dan prasarana maupun dengan melakukan program kegiatan dalam mengukur atau menilai bagaimana kualitas pelayanan terkait IMB yang kegitan tersebut adalah "Survey Kepuasan Masyarakat" (SKM) kegiatan ini mengsurvey masyarakat yang telah terbit izinnya dengan mengacu kepada 14 unsur pelayanan yang menjadi bahan untuk mengukur bagaimana kualitas pelayanan itu sendiri dengan demikian kualitas pelayanan dalam hal 
pemberian IMB nanti dirasakan oleh masyarakat di tahun 2017 sampai sekarang ini.

Berbicara mengenai kualitas pelayanan dapat kita lihat melalui indikator kualitas pelayanan yang akan dijelaskan sebagai berikut :

a) Penampilan aparatur dalam melayani pelanggan

Seperti yang sekarang ini sudah terlihat bagus seperti yang kita lihat sekarang ini hampir semua pegawai pada DPMPTSP sudah berpenampilan bagus dan rapih sehingga msyarakat merasa puas atas penampilan aparatur terkait pelayanan perizinan

b) Mengenai kenyaman tempat melakukan pelayanan

Seperti yang kita ketahui bahwa setelah DPMPTSP resmi terbentuk pada tahun 2016, DPMPTSP nulai melakukan pengadaan sarana dan prasarana untuk memberikan kenyamana tempat pelayanan bagi pelanggan yang ingin mengurus IMB atau izin yang lainnya.

c) Kemudahan dalam proses pelayanan

DPMPTSP dalam memudahkan masyarakat dalam mengurus IMB yaitu dengan adanya website dimana untuk mempermudah masyarakat mendapatkan informasi seputar persyaratan IMB dan alur pengurusan IMB, selain itu DPMPTSP memiliki suatu inovasi yakni antar jemput berkas sampai terbitnya sertifikat IMB dan itu dilakukan agar masyarakat yang tinggal di wilayah jauh dari kota polewali tidak perlu lagi datang ke DPMPTSP kerena adanya inovasi antar jemput sehingga masyarakt tersebut dapat memiliki IMB dan juga DPMPTSP dalam hal kemudahan dimana masyarakat yang tinggalnya bukan wilayah yang jauh ada juga inovasi dimana pelanggan yang telah selesai izin IMB akan ditelfon oleh petugas pelayanan atau front office bahwa sertifikat IMB telah terbit.

d) Kedisiplinan aparatur dalam melakukan pelayanan

Dapat dinilai belum sepenuhnya baik karena masih dapat kita temukan aparatur baik itu yang tetap maupun tidak tetap (honorer) yang tidak sesuai dengan ketentuan yang ada seperti jam 08.00 atau 08.30 itu semua pegawai sudah harus ada di kantor tetapi faktanya bahwa masih ada pegawai yang datang ke kantor yaitu jam 10.00 bahkan di jam kedua atau 14.00/14.30 masih saja ada seperti itu yang tidak tepat waktu sehingga terkadang pelanggan yang ingin mengurus IMB atau izin yang lain menjadi tertunda.

e) Kecermatan dalam melayani

Aparatur dalam hal kecermatan dalam melayani masyarakat yaitu hampir semua sudah cermat namun terkadang yang masih kurang cermat 
itu seperti pegawai honorer yang kurang paham apa yang dibutuhkan oleh pelanggan karena pegawai tersebut masih muda sehingga masih perlu arahan dan pelatihan.

\section{Faktor-Faktor Apa Yang Berpengaruh Terhadap Kualitas Pelayanan Izin Mendirikan Bangunan (IMB)}

Berbicara mengenai faktor yaang mempengaruhi kualitas pelayanan IMB tidak terlepas dari kinerja pegawai dalam memberikan pelayanan kepada masyarakat. Setelah apa yang didapat oleh penulis dengan hasil penelitian di DPMPTSP menyangkut faktor yang mempengaruhi kualitas pelayanan yang terdiri dari faktor pendukung dan penghambat dan untuk lebih jelasnya telah diuraikan sebagai berikut:

a. Faktor Pendukung

Adapun yang menjadi faktor pendukung dalam memberikan pelayanan kepada masyarakat agar lebih berkualitas lagi dan lebih efektif terkait pemberian IMB pada kantor DPMPTSP Kabupaten Polewali Mandar sebagai berikut:

1) Peran Aparatur DPMPTSP

Sebagai unsur pendukung pelaksanaan dalam memberikan pelayanan perizinan terkait IMB tentunya peran aparatur sangat dibutuhkan agar setiap prosese kegiatan pelayanan yang dilaksanakan berjalan sesuai dengan ketentuan yang ditetapkan. Peran aparatur sangat dipengaruhi juga oleh sikap ramah melayani,sikap rasa adil dalam melayani masyarakat,kemudahan dalam pelayanan, dana pelayanan yang tepat.Seperti yang kita ketahui OPD DPMPTSP Kabupaten Polewali Mandar memiliki struktur organisasi sebagai faktor utama berjalannya birokrasi pemerintahan yang telah tercantum di dalamnya susunan aparatur DPMPTSP dan juga dapat diketahui pembagian tugas masing-masing aparatur sesuai dengan bidangnya.

2) Peraturan atau Kebijakan

Setiap kegiatan atau pekerjaan yang dilakukan harus berdasarkan pada peraturan ataupun kebijakan yang ada, dan itu sangat penting karena kegiatan tidak akan berjalan lancar apabila tidak ada asas yang mengikat atau kebijakan mengenaipelayanan perizinan dalam hal ini Izin Mendirikan Bangunan (IMB). Sama halnya seperti SOP dan Standar Pelayanan yang merupakan kebijakan yang menjadi pedoman aparatur dalam melaksanakan suatu pekerjaan. Selain dari SOP dan Standar Pelayanan yang mendukung penyelenggaraan pelayanan terkait IMB adapula peraturan yang menjadi dasar rencan 
kegiatan seperti PERDA, Peraturan Bupati, dan PERMENDAGRI dan ini semua menjadi pendukung terselenggaranya suatu pelayanan perizinan agar lebih berkualitas lagi kedepannya.

3) Sosialisasi

Sosialisasi mengenai pemberian IMB merupakan salah satu langkah yang dilakukan Pemerintah Daerah dan OPD DPMPTSP untuk memberikan pemahaman secara akurat dan jelas kepada masyarakat tentang pentingnya memiliki IMB sebagai suatu kewajiban saat ingin mendirikan suatu bangunan tempat tinggal atau sejenis bangunan yang lainnya. Sosialisasi ini juga salah satu upaya untuk memberitahukan kepada masyarakat bahwa IMB wajib hukumnya untuk segera mengurus karena, telah diatur pada peraturan perundang-undangan yang berkaitan dengan IMB. Selain itu kegiatan sosialisasi telah dilakukan oleh DPMPTSP sejak beberapa tahun terakhir dari tahun 2017 sampai 2018 dengan ini sosialisasi dilakukan untuk memberikan kemudahan, ketentuan, arahan menyangkut mekanisme prosedur pelayanan, persyaratan administrasi. Adapun yang perlu kita perhatikan jikalau tidak memiliki IMB ialah bangunan yang kita dirikan akan tidak mendapat kepastian hukum dari Pemerintah dan pastinya bangunan tersebut tidak mendapat perlindungan apabila suatu saat terjadi sesuatu pada bangunan tersebut. Sehingga kedepannya Pemerintah akan lebih menggiatkan kegiatan sosialisasi ini agar semua masyarakat peduli dan sadar pentingnya memiliki IMB.

b. Faktor Penghambat

Adapun yang menjadi hambatan terhadap kualitas pelayanan Izin Mendirikan Bangunan yang menjadi penyebab kurangnya kualitas pelayanan. Sehingga penulis menguraikan beberapa faktor penghambat kualitas pelayanan.

1) Masih adanya kendala yang ditemukan pada tim teknis.

Tim teknis dalam hal ini Dinas PU dan Penataan Ruang merupakan salah satu OPD yang mempunyai peranan dalam diterbitkannya IMB. Selain itu Setiap bangunan yang kita dirikan sebelumnya harus memiliki IMB dan tentunya tim teknis disini yang mengeluarkan rekomendasi teknis setelah diproses berkas permohonan dan dinyatakan dapat diterima setelah itu dilanjutkan ke DPMPTSP untuk diproses lagi, dan berarti lokasi bangunan tersebut dapat di proses untuk diterbitkannya Dokumen IMB.Dinas PUPR yang mengetahui pengukuran dan perhitungan lokasi bangunan yang 
mendapat IMB dan juga menentukan apakah permohonan perizinan dapat ditindak lanjuti untuk diproses pada penerbitan IMB atau tidak. Sehubungan dengan hal tersebut bahwa salah satu hambatan yang mempengaruhi kualitas pelayanan yaitu terdapat di tim teknis itu sendiri.

Menurut informasi yang didapat oleh penulis di DPMPTSP lewat pegawai DPMPTSP Kepala Bidang Pengolahan dan Penetapan yang mengatakan "hambatan yang sering terjadi dalam menerbitkan IMB yaitu pada tim teknis yang mengelurkan rekomendasi teknis karena saat diperiksa surat pengantar setelah itu di proses berkas permohonan terjadi pembatalan atau penolakan yang disebabkan karena tidak memenuhi standar ketentuan untuk lokasi bangunan tersebut akhirnya penerbitan IMB tidak dilanjutkan.

2) Masih banyaknya masyarakat tidak peduli tentang pentingnya setiap bangunan memiliki IMB.

Setelah apa yang diungkapkan oleh Kepala Bidang Pengolahan dan Penetapan yang menurutnya masih banyak masyarakat kita yang belum mempunyai IMB hal tersebut disebabkan karena mereka masih menganggap tidak terlalu penting dan tidak memperdulikan bahwa kewajiban mengurus IMB, dan apapun jenis bangunan tersebut.

Banyaknya masyarakat yang mengurus IMB berarti dapat diketahui bagaimana kualitas pelayanan IMB pada DPMPTSP Kabupaten Polewali Mandar dan adakah peningkatan atau tidak karena ini sangat berpengaruh seberapa besar masyarakat yang telah memiliki IMB dengan Survey Kepuasan Masyarakat yang dilakukan oleh DPMPTSP untuk mendapatkan hasil, apakah kualitas pelayanan mendapat mutu pelayanan yang sangat baik, baik, kurang baik atau tidak baik.

\section{KESIMPULAN}

DPMPTSP dalam memudahkan masyarakat dalam mengurus IMB yaitu dengan adanya website dimana untuk mempermudah masyarakat mendapatkan informasi seputar persyaratan IMB dan alur pengurusan IMB. Selain itu DPMPTSP memiliki suatu inovasi yakni antar jemput berkas sampai terbitnya sertifikat IMB. Dan itu dilakukan agar masyarakat yang tinggal di wilayah jauh dari kota polewali tidak perlu lagi datang ke DPMPTSP kerena adanya inovasi antar jemput sehingga masyarakt tersebut dapat memiliki IMB. Masyarakat yang tinggalnya bukan wilayah yang jauh ada juga inovasi dimana pelanggan yang telah selesai izin IMB akan ditelfon oleh petugas pelayanan atau front office bahwa sertifikat IMB telah terbit. 
faktor-faktor yang mempengaruhi kualitas pelayanan IMB berupa; faktor pendukung, yakni peran aparatur DPMPTSP, peraturan atau kebijakan, serta sosialisasi; faktor penghambat, yakni masih adanya kendala yang ditemukan pada tim teknis, dan masih banyaknya masyarakat tidak peduli tentang pentingnya setiap bangunan memiliki IMB.

\section{SARAN}

Artikel ini tentunya terlalu singkat untuk menjelaskan banyak hal tentang Studi Tentang Kualitas Pelayanan Izin Mendirikan Bangunan (IMB) Pada Dinas Penanaman Modal Dan Pelayanan Terpadu Satu Pintu di Kabupaten Polewali Mandar. Masih banyak aspek yang perlu dieksplorasi lebih dalam untuk memperoleh gambaran konfrehensif tentang Kualitas Pelayanan Izin Mendirikan Bangunan (IMB) pada Dinas Penanaman Modal dan Pelayanan Terpadu Satu Pintu di Kabupaten Polewali Mandar.

\section{DAFTAR PUSTAKA}

Swastha, Basu \& Irawan. 1983. Manajemen Pemasaran Modern. Mamasa : Liberty.

Himna, Edwin Ismedi. 2013. Daya Tarik Wisatawan. Kedaulatan Rakyat (19 Januari 2013).

Garjito, Gunaning. 2005. Strategi Promosi Wisata Pada Dinas Pariwisata dan Kebudayaan Kabupaten Gunung Kidul. Skripsi. FIS-UNY.

Karyono, Hari. 1997. Kepariwisataan. Jakarta: PT. Remaja Rosdakarya.

Rachmawati, Indria Desy. 2005. Strategi Publik Relations Dinas Pariwisata dan Kebudayaan Kabupaten Mamasa. Skripsi. FIS-UNY

Gitosudarmo, Indriyo. 2008. Manajemen Pariwisata. Mamasa : BPFE.

Kesrul. 2003. Penyelenggaraan Operasi Perjalanan Wisata. Jakarta : Garasindo.

Moleong, Lexi J. 2002. Metode penelitian Kualitatif. Bandung: Remaja Rosdakarya.

Miles M. B. dan Huberman, A. M. 1992. Analisis Data Kualitatif. Penerjemah: Tjetjep Rohendi Rohini. Jakarta : Universitas Indonesia.

Desky, M. A. 1991. Manajemen Perjalanan Wisata. Mamasa : Adicita Karya Nusa.

Yoeti. Oka A. 1996. Pengantar Ilmu Pariwisata. Bandung: Angkasa.

Effendy, Onong Uchjana. 1992. Hubungan Masyarakat Suatu Studi Komunikologis. Bandung: PT. Remaja Rosdakarya. 
Kotler, Philip. 2001. Prinsip-prinsip Pemasaran. Jakarta: Erlangga

Nyoman S, Pendit. 2002. Ilmu Pariwisata Sebuah Pengantar Perdana. Jakarta: Pradnya Paramita.

Lupiyoadi, Rambat. 2006. Manajemen Pemasaran Jasa. Jakarta: Salemba empat.

Wahab, Salah. 2003. Manajemen Kepariwisataan. Jakarta: Pradnya Paranita. 